\title{
A New Approach to Assess the Built Environment Risk under the Conjunct Effect of Critical Slow Onset Disasters: A Case Study in Milan, Italy
}

\author{
Juan Diego Blanco Cadena ${ }^{1}\left(\mathbb{D}\right.$, Nicola Moretti ${ }^{1,+}{ }^{\circledR}$, Graziano Salvalai ${ }^{1}\left(\mathbb{D}\right.$, Enrico Quagliarini ${ }^{2, *} \mathbb{C}$, \\ Fulvio Re Cecconi ${ }^{1}$ (D) and Tiziana Poli ${ }^{1}$ (D) \\ 1 ABC Department, Politecnico di Milano, 20133 Milan, Italy; juandiego.blanco@polimi.it (J.D.B.C.); \\ nicola.moretti@polimi.it (N.M.); graziano.salvalai@polimi.it (G.S.); fulvio.rececconi@polimi.it (F.R.); \\ tiziana.poli@polimi.it (T.P.) \\ 2 DICEA Department, Università Politecnica Delle Marche, 60131 Ancona, Italy \\ * Correspondence: e.quagliarini@staff.univpm.it \\ + Current address: Institute for Manufacturing, Department of Engineering, University of Cambridge, \\ 17 Charles Babbage Road, Cambridge CB3 0FS, UK.
}

Citation: Blanco Cadena, J.D.; Moretti, N.; Salvalai, G.; Quagliarini, E.; Re Cecconi, F.; Poli, T. A New Approach to Assess the Built Environment Risk under the Conjunct Effect of Critical Slow Onset Disasters: A Case Study in Milan Italy. Appl. Sci. 2021, 11, 1186. https://doi.org/10.3390/app11031186

Academic Editor:Asterios Bakolas

Received: 11 January 2021

Accepted: 25 January 2021

Published: 28 January 2021

Publisher's Note: MDPI stays neutral with regard to jurisdictional clai$\mathrm{ms}$ in published maps and institutional affiliations.

Copyright: (C) 2021 by the authors. Licensee MDPI, Basel, Switzerland. This article is an open access article distributed under the terms and conditions of the Creative Commons Attribution (CC BY) license (https:// creativecommons.org/licenses/by/ $4.0 /)$.

\begin{abstract}
Citizens in dense built environments are susceptible to the simultaneous occurrence of Slow Onset Disaster (SLOD) events, being particularly prone to increasing temperatures and air pollution. Previous research works have assessed these events' arousal separately and have identified when their intensity is critical. However, few have integrated their analysis, possibly limited by the quality and granularity of available data, the accessibility and distribution of sensors, and measurements not emulating the surroundings of a pedestrian. Thus, this work performed an outdoor meso-scale multi-hazard-based risk analysis to study the aggregated effects of the SLODs mentioned above. The study was carried out to narrow down the time-frames within 2019 in which these two events could have affected citizens' health the most. A weighted fuzzy logic was applied to superimpose climatic (temperature, humidity, wind speed, and solar irradiance) and air quality (particulate matter, ozone, and ammonium) distress (true risk) on an hourly basis, allocated using set healthy and comfortable ranges for a specific dense urban climate context within Milan (Italy), processing data from Milano via Juvara station. The findings show that sensitive groups were at risk of high temperature and pollution separately during $26 \%$ and $29 \%$ of summer and mid-season hours, respectively; while multi-hazard risk would arise during $10.93 \%$ of summer and mid-season hours, concentrated mainly between 14:00 and 20:00.
\end{abstract}

Keywords: risk assessment; climate change; health; heat stress; AQI

\section{Introduction}

The United Nations [1] reported in 2018 that 55\% of the world's population was already living in highly urbanized areas and that this ratio is projected to grow to $68 \%$ by 2050. These projections for the urban population, coupled with the projected health threats identified by the World Health Organization (WHO) [2,3] due to climate change, foresee that around 6.7 billion people are at great risk. Hence, identifying the frequency, intensity, and extent of the hazard risk of these threats has become a pillar in the worldwide effort to hold back the consequences of climate change, reflected by the Sustainable Development Goals and in particular by the following three topics: good health and wellbeing, sustainable cities and communities, and climate action [4].

In 2014, the WHO analyzed and projected the effects of climate change on health, identifying heat-related mortality as among the foreseen death risks of the largest impact [2]. Later on, in 2016, the WHO also reported the extent of air pollutants' concentration and their severe potential effect on the decay of health condition and the increase in mortality. 
For instance, the WHO [2] estimated that by 2030, more than 92,000 additional heat-related deaths are expected; and more than 255,000 for 2050 if no measures are taken. Furthermore, Lee and Kim [5] studied the case of South Korea, comparing the 1992 to 2010 period with the 2090s projections; resulting in a $4 \times$ or $6 \times$ increase in temperature-related mortality. On the other hand, for air pollutants' concentration, Jackson et al. [6] presented a case study in Washington, in which it was reported that for people over 45 years old, there was an increase of $0.46-1.50 \%$ in the risk of mortality for every 10 parts per billion (ppb) increase in eight hour average ozone concentrations.

Climate change itself is an active and slow process, and within this context, increasing temperatures and higher air pollution have been classified in the same way. Both have been allocated into the definition of Slow-Onset Disasters (SLODs) [7], which are easy to perceive, and predict, but harder to mitigate. The arousal frequency and intensity of SLODs' evidence is larger in the urbanized context [8], and this evidence can be worsened given the inherent properties of the Built Environment (BE). A recent report by the Urban Climate Change Research Network [9] shows that mean annual temperatures in 39 cities around the world have increased at a rate of 0.12 to $0.45^{\circ} \mathrm{C}$ per decade over the 1961 to 2010 time period. Furthermore, a recently audited air pollution report [10], which surveyed more than 4300 cities worldwide in 2015 , concluded that only $20 \%$ of the urban population was reported to live in areas that comply with the WHO's established unhealthy concentrations of $P M_{2.5}$. The average particulate air pollution levels in these cities were found to be 4-15-times higher than the WHO air quality guideline limit levels. Dense urban areas increase the risk of the two above-mentioned SLODs for the following main reasons: (1) reduced evaporation, transpiration, and shading, due to limited green areas and disadvantageous geometry; (2) increased surface temperatures with high thermal capacity and/or low albedo; and (3) increased air stagnation due to diminished wind speed [11-15], thus making every portion of the city (e.g., neighborhood) react/provide a different meso-climate to the people within it.

Extensive research has been dedicated to studying these variations with different approaches, at different scales, and with different tools. Udristioiu et al. [16] and Sassi and Fourri [17] are recent examples on how to study the satellite remote sensing data, gathering information on Land Surface Temperature (LST) from infrared radiation measures. Other case studies, such as the one presented by Khamchiangta et al. [18], have used large geographical data to study the land use land coverage and correlated these conditions to estimate the possible response to undisturbed climatic readings (e.g., weather data); also, these databases have been combined with geographical tools (e.g., Geographic information Systems (GISs)) and small-scale on-site measurements to communicate actual point-in-time conditions [19-21].

However, these analyses are limited by the availability, quality, granularity, and applicability of data describing what is the real perception of a pedestrian, or a building occupant, as his/her surroundings can drastically modify the perception of climatic and air quality distress [22,23]. Moreover, integrated and multi-hazard analysis at the meso-scale is hampered by the distribution of sensors and the fact that, mostly, the data collection location does not always gather more than one parameter category (e.g., weather and pollutants), which makes the superposition of the effects hardly applicable.

Therefore, this work intends to propose and perform a preliminary multi-hazard risk analysis of northern Italy (i.e., Milan), using available open-source climate and air quality databases supported by the Lombardy Regional Environmental Protection Agency (ARPA Lombardia) [24]. Milan was considered a relevant location where a large population density is found (large risk exposure) and both considerable increasing temperatures and the decay of air quality and the increase of pollution converge (large risk hazard), based on the preliminary assessment analysis carried out by Salvalai et al. [25] using demographic data from the Italian National Institute of Statistics (ISTAT) [26] and historical temperature and particulate matter measurements from EEA [27,28]. 
In particular, the study presented in this paper is concentrated on assessing the overall increasing temperatures and air pollution SLODs' risk frequency for the least resilient population: demographic groups that are more prone to suffer severe health consequences when exposed to adverse environmental conditions. Moreover, critical hazard risk timeframes (including daily profiles) are established to acknowledge and communicate those moments of the year in which people are and probably will continue to be critically at risk of their health being affected if exposed to these conditions.

\section{Materials and Methods}

This work intends to propose a replicable procedure at the city and neighborhood scale, based on available and accessible data repositories (i.e., open data).

\subsection{Temperature-Related Risk RiskT}

There are few indexes or metrics that integrate the weather parameters with ease to understand the proper sensation of people outdoors. Most of them require rather extensive on-site surveys to feed the model with several measured quantities, or to feed the virtual model for lengthy computer simulations. Fortunately, indexes such as the Universal Thermal Climate Index (UTCI) [29] can be used in a simplified manner, which requires rather commonly surveyed parameters to estimate the pedestrian's sensation of his/her surroundings; that is:

- $\quad$ Dry bulb air temperature $\left(t_{d b-a i r}\right)$

- Mean Radiant Temperature (MRT)

- $\quad$ Relative Humidity $(R H)$

- $\quad$ Air/wind velocity $\left(V_{a}\right)$

However, for a preliminary and large-/meso-scale outdoor human-centered analysis, there is limited information on where the pedestrian is or will be located and how he/she is or will be exposed to solar and emitted surface-heat radiation. Thus, computing spatiallocation variables, such as MRT and spot-specific $V_{a}$, goes beyond the scope of this study. Moreover, established simplifications for MRT estimations (as the ones listed in ASHRAE 55-2017 [30] for an indoor assessment) cannot be applied given the exposure to direct solar radiation, high registered $V_{a}$, high variance of the type of pedestrian activity, and the clothing worn.

Therefore, for surveyed data obtained from open-source data such as national, regional, or local weather station network repositories, another approach is needed to anticipate and identify potential moments during the year in which pedestrians can be more susceptible to risk. A susceptible temperature-related risk is then interpreted as the conjoint frequency of undesirable conditions of $t_{d b-a i r}$, solar radiation $\left(I_{t o t}\right), R H$, and $V_{a}$.

To do so, a simple Boolean and weighting analysis was performed following fuzzy logic; that is, for every hour of the year, the condition of each parameter was verified; if so, this was allocated a certain risk weight according to the parameter's influence on thermal stress, and all the weights were summed for every single Hour Of the Year (HOY) (see Equation (1)).

$$
R i s k T_{\text {HOY }}=\left(T_{\text {bool }} * T_{\text {weight }}+I_{\text {bool }} * I_{\text {weight }}+R H_{\text {bool }} * R H_{\text {weight }}+V_{\text {bool }} * V_{\text {weight }}\right)_{\text {HOY }}
$$

\subsubsection{Undesired Boolean Conditions}

The Boolean is considered true (i.e., $i_{b o o l}=1$ ) when certain weather conditions fall outside the comfort ranges. Based on indoor and outdoor comfort assessment metrics or indexes, these true ranges were established as:

- $t_{d b-a i r}$ is recorded above $26{ }^{\circ} \mathrm{C}$ (only heat stress $(T)$ is considered);

- $I_{\text {tot }}$ is measured over $300 \mathrm{~W} / \mathrm{m}^{2}$;

- $\quad R H$ is registered outside a $30-70 \%$ range; and 
- $\quad V_{a}$ speed is below $2 \mathrm{~m} / \mathrm{s}$.

An additional condition was included to avoid false positive results, reporting heatrelated distress when temperatures are below $18^{\circ} \mathrm{C}$. Hence, the Boolean shall be considered negative (i.e., $T_{b o o l}=-1$ ).

\subsubsection{Weighting Factors}

Based on the effect of the parameter's significance on outdoor thermal stress perception, factors summing to 1 were allocated, giving larger values to those directly related to sky heat exchange (i.e., $T_{d b-a i r}$ and $I_{t o t}$ ) [22]. Further development of the research work includes a fine-tuning of these weights:

- for temperature, $T_{\text {weight }}=0.4$ is used, given that the temperature is perhaps the most relevant parameter;

- for radiation, $I_{\text {weight }}=0.3$ is used, given that direct solar radiation falling on a body can significantly alter its heat exchange; and

- for both air humidity and wind speed, $R H_{\text {weight }}=V_{\text {weight }}=0.15$ is given, as they can intensify or alleviate one's perception of the previous conditions.

\subsubsection{Comparison with the Simplified UTCI Calculation}

To validate the suitability of the assessment process and the weight allocation, the values estimated were compared to the results obtained with the simplified outdoor thermal comfort UTCI calculation.

UTCI values were computed using the UTCI Python code produced by Ladybug Tools [22] based on the Fortran code provided by Brode et al. [29], but considering that $t_{d b-a i r} \approx M R T$. The validation was considered successful based on the difference in the number of hours classified as at risk of high thermal stress, and the accuracy was computed using a classification-accuracy assessment (see Equation (2)).

$$
\text { Accuracy }=\frac{T P+T N}{T P+T N+F P+F N}
$$

where each of the following variables is:

- TP the number of True Positive values;

- $\quad T N$ the number of True Negative values;

- $\quad F P$ the number of False Positive values; and

- $\quad F N$ the number of False Negative values.

Heat distress was set to be expected, for sensitive groups, when:

- $\quad$ RiskT $>0.5$

- $\quad U T C I>26^{\circ} \mathrm{C}$

These weights, ranges, and thresholds were set based on the regulations enforced in the case study analyzed, the available databases, and the assumed pedestrian condition within a narrow urban canyon (i.e., shaded and wind protected).

\subsection{Pollution-Related Risk}

The Air Quality Index $(A Q I)$ was used as an established and widely used air pollution metric [31]; also, it can be estimated with ease based on the data gathered at air quality weather stations. The metric is based on the concentration of the main health affect-related pollutants; and also, they can be compared in a unique scale. When more than one pollutant is studied, the communicated $A Q I$ is the largest value.

The $A Q I$ calculation is based on Equation (3), which depends on the current pollutant concentration $\left(C_{p}\right)$ and the data collected in Table 1; which contains the pollutant concentration Break Points $\left(B P_{H i}\right.$ and $\left.B P_{L o}\right)$ and the $A Q I$ range limits $\left(I_{H i}\right.$ and $\left.I_{L o}\right)$. The pollutant concentrations are normally evaluated from an 8 hour (for $\mathrm{O}_{3}$ and $\mathrm{NH}_{3}$ ) or 24-h exposure (for $P M_{2.5}$ and $P M_{10}$ ); thus, depending on the case, a moving mean of the previous $8 \mathrm{~h}$ is 
computed, or $24 \mathrm{~h}$ values are assumed for the $24 \mathrm{~h}$ period, allowing comparing the results on an hourly basis.

The selected weather and air quality station monitors only some substances; hence, $\mathrm{O}_{3}, \mathrm{NH}_{3}, \mathrm{PM}_{2.5}$, and $\mathrm{PM}_{10}$ were analyzed.

$$
A Q I_{p_{i}}=\frac{I_{H i}-I_{L o}}{B P_{H i}-B P_{L o}} *\left(C_{p}-B P_{L o}\right)+I_{L o}
$$

Table 1. Parameters needed for $A Q I$ calculation for an 8 hour or 24 hour exposure period (extracted and edited from the Environmental Protection Agency (EPA) guidelines [31]). BP, Break Point.

\begin{tabular}{|c|c|c|c|c|c|}
\hline \multirow[b]{2}{*}{$\mathrm{O} 3$ (ppm) } & \multicolumn{2}{|c|}{ BPs } & \multirow[b]{2}{*}{$\mathrm{NH}_{3}\left(\mu \mathrm{g} / \mathrm{m}^{3}\right)$} & \multirow[b]{2}{*}{ AQI } & \multirow[b]{2}{*}{ Category } \\
\hline & $\mathrm{PM}_{10}\left(\mu \mathrm{g} / \mathrm{m}^{3}\right)$ & $\mathrm{PM}_{2.5}\left(\mu \mathrm{g} / \mathrm{m}^{3}\right)$ & & & \\
\hline $0.000-0.064$ & $0-54$ & $0.0-15.4$ & $0-200$ & $0-50$ & Good \\
\hline $0.065-0.084$ & $55-154$ & $15.5-40.4$ & $201-400$ & $51-100$ & Moderate \\
\hline $0.085-0.104$ & $155-254$ & $40.5-65.4$ & $401-600$ & $101-150$ & Unhealthy for sensitive groups \\
\hline $0.105-0.124$ & $255-354$ & $65.5-150.4$ & $601-800$ & $151-200$ & Unhealthy \\
\hline \multirow[t]{3}{*}{$0.125-0.374$} & $355-424$ & $150.5-250.4$ & $801-1200$ & $201-300$ & Very unhealthy \\
\hline & $425-504$ & $250.5-350.4$ & $1201-1800$ & $301-400$ & Hazardous \\
\hline & $505-604$ & $350.5-500.4$ & $>1800$ & $401-500$ & Hazardous \\
\hline
\end{tabular}

As performed in Section 2.1, the number of hours in which the residents of the nearby area are exposed to hazard risk were computed, assuming the risk threshold for low air quality sensitive groups as $A Q I>100$ (Table 2).

Table 2. Sensitive groups at risk by pollutant type when the $A Q I$ goes above 100 for an 8 hour $\left(O_{3}\right)$ or 24 hour $\left(P M_{10}\right)$ average exposure period (extracted and edited from the EPA guidelines [31]).

\begin{tabular}{cc}
\hline Pollutant & Demographic Groups at Higher Risk \\
\hline Ozone $\left(\mathrm{O}_{3}\right)$ & People with lung disease, children, elderly, and people who are active outdoors \\
Particulate matter $\left(P M_{2.5}\right)$ & People with heart or lung disease, elderly, and children \\
Particulate matter $\left(P M_{10}\right)$ & People with heart or lung disease, elderly, and children \\
\hline
\end{tabular}

\subsection{Air Temperature and Pollution Confluence Risk}

Given that the results for both RiskT and $A Q I$ were allocated into 2 macro categories (i.e., at risk and no risk) and that they were reported hourly, the confluence risk was estimated as the product of the Boolean of both risks' existence (i.e., RiskT $>0.5$ and $A Q I>100)$.

Then, the recurrence of these conditions was estimated as the ratio between the hours of risk presented, during:

- $\quad$ the whole year $(8760 \mathrm{~h})$;

- $\quad$ the summer period only (15 June-15 September, $2208 \mathrm{~h}$ );

- both the mid-season and summer period (15 April-15 October, $4392 \mathrm{~h}$ ); and,

- mid-season (15 April-15 June and 15 September-15 October, 2184 h).

\subsection{Case Study Description}

Profiting from the database made available by the regional environmental monitoring institution (ARPA Lombardy Agency [24]), it was possible to retrieve air quality and weather data from a single, but relevant, data source (i.e., Milano via Juvara) near a university district in the city of Milan, Italy (Figure 1). These data were collected and elaborated only for 2019, given the yearly data's completeness and recentness, as described in the following sections.

The weather and air quality station Milano via Juvara is located within the Buenos Aires-Venezia Local Identity Unit (NIL), a neighborhood characterized by low green area 
coverage and mid-to-high built density, as documented by the Municipality of Milan [32] (see Figure 1). It was expected that the data collected would provide evidence to assume that the area has a low heat and pollution management capacity, which puts its inhabitants at a relevant increasing temperatures and air pollution SLODs risk.

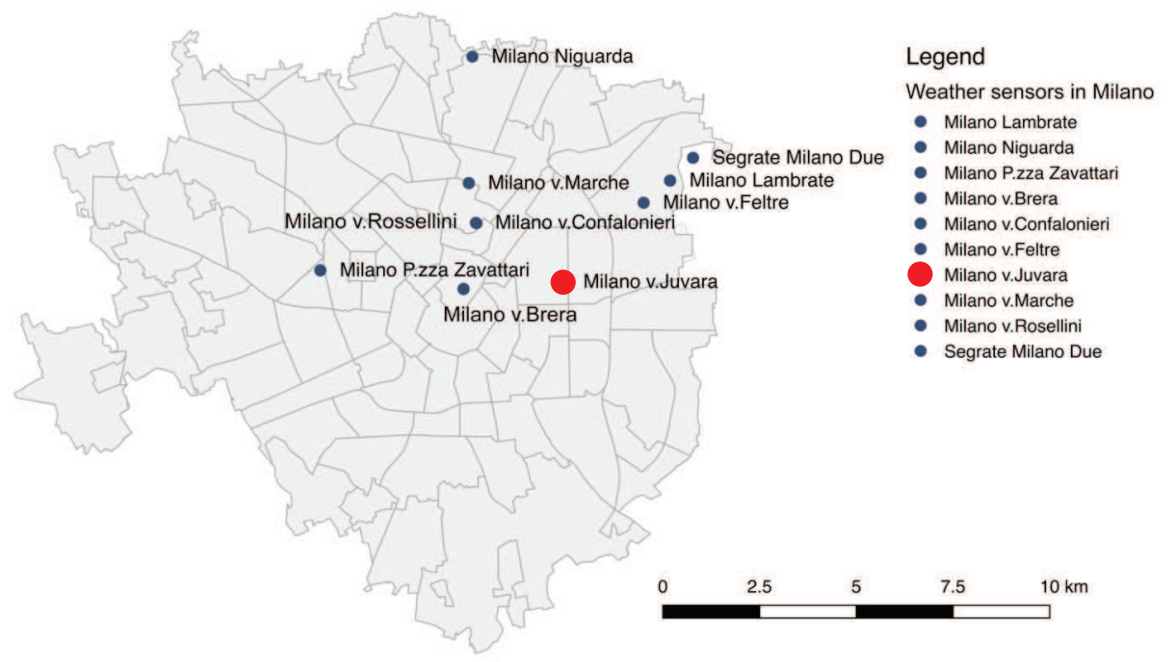

Figure 1. Location of the Milano via Juvara station within the city of Milan divided by NILs.

\section{Results}

To understand the frequency distribution on a yearly basis, the results are presented on $24 \times 365$ heat maps for every risk type and daily frequency distribution charts for their confluence (e.g., Figure 2). It was considered that summer is between Day Of the Year (DOY) 166 and 258; and winter ends and starts on DOYs 105 and 288, respectively.

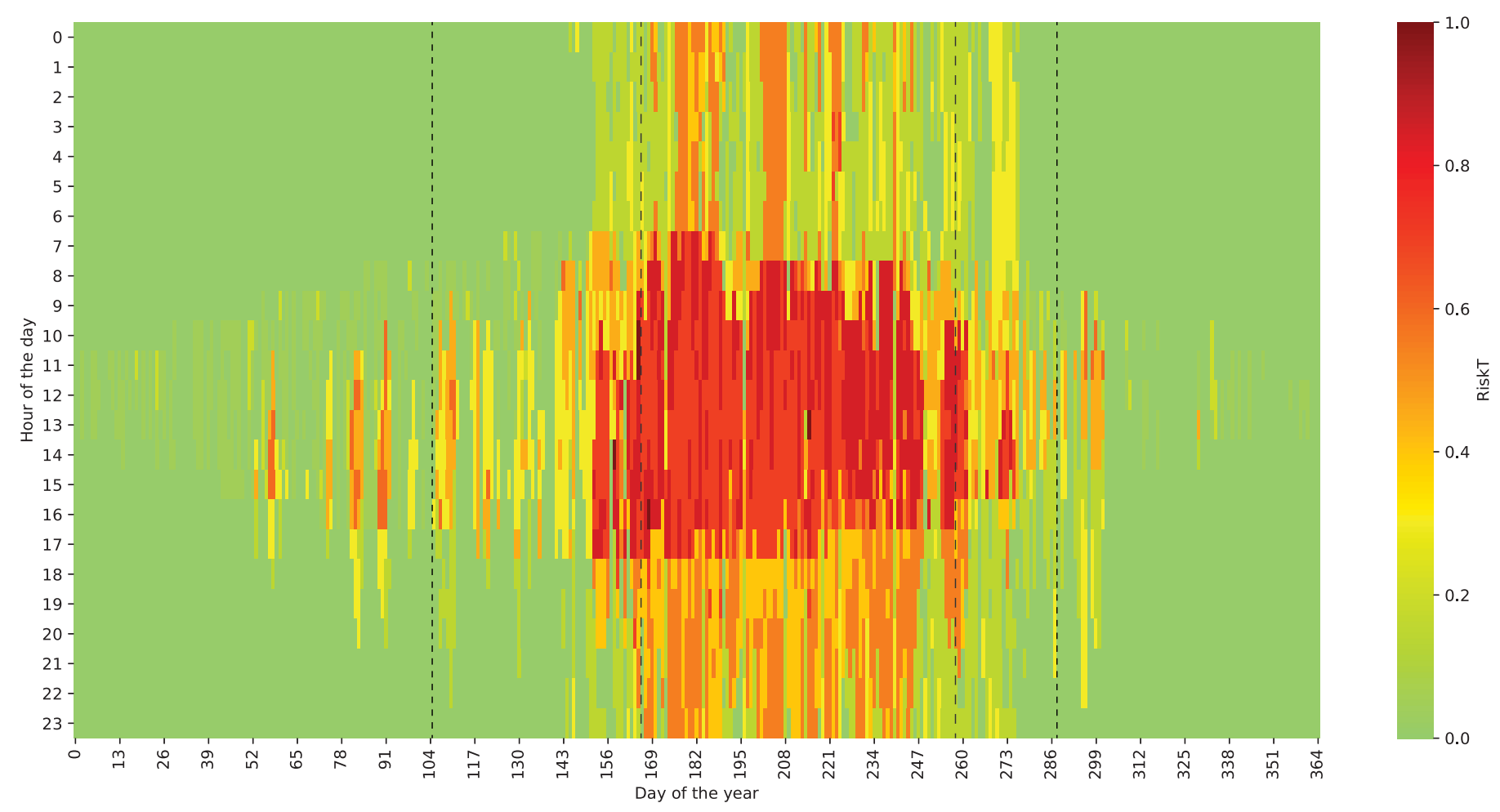

Figure 2. Degree of RiskT from values monitored in 2019 at the station Milano v. Juvara, based on the confluence of disadvantageous conditions of $t_{d b-a i r}, I_{t o t}, R H$, and $V_{a}$; which are closely related to the SLOD of increasing temperatures. 


\subsection{Meaningful Thermal Stress Risk Frequency}

Following the methodology described in Section 2, RiskT and UTCI values were computed for each hour of the data collected from M. v. Juvara station during 2019. These are plotted in Figures 2 and 3 to qualitatively analyze how this thermal-stress-related risk was manifesting, and quantitative reported frequency data are summarized in Table 3.

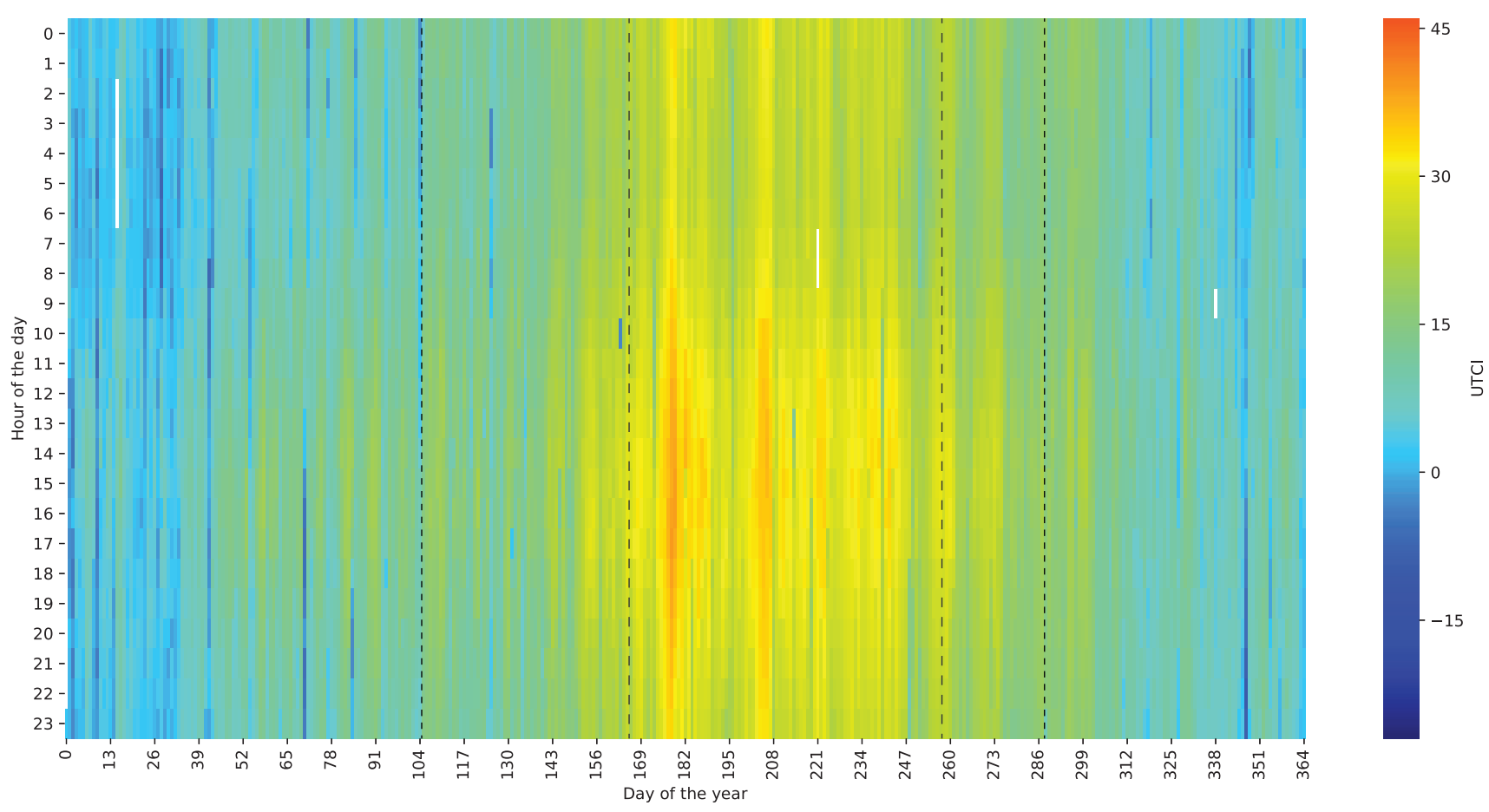

Figure 3. Degree of thermal stress expressed in UTCI, based only on the values for 2019 from Milano v. Juvara of $t_{d b-a i r}$, $R H$, and $V_{a}$.

Table 3. Summary results of the allocated thermal stress, when using RiskT $>0.5$ or UTCI $>26$ as the criterion, differentiated by season.

\begin{tabular}{cccccc}
\hline & \multicolumn{2}{c}{ RiskT } & \multicolumn{2}{c}{ UTCI } \\
\hline Season & $\begin{array}{c}\text { \# of } \\
\text { Hours }\end{array}$ & Hours at Risk & Ratio & Hours at Risk & Ratio \\
& & & & & \\
\hline Whole year & 8760 & 1324 & $15.11 \%$ & 1343 & $15.33 \%$ \\
Summer and mid & 4392 & 1295 & $29.49 \%$ & 1343 & $30.58 \%$ \\
Summer & 2208 & 1145 & $26.21 \%$ & 1253 & $28.69 \%$ \\
Mid & 2184 & 150 & $3.42 \%$ & 90 & $2.05 \%$ \\
Winter & 4368 & 29 & $0.66 \%$ & 0 & $0.00 \%$ \\
\hline
\end{tabular}

The risk for both RiskT and UTCI is notably concentrated in summer $(29.49 \%$ and $30.58 \%$ ). However, Figure 3 displays that for UTCI, rare and low intensity risk arose during the mid-season $(2.05 \%)$, and no risk was registered during winter. On the other hand, Figure 2 presents that RiskT would communicate a higher risk intensity in summer, a larger frequency and intense risk for the mid-season $(3.42 \%)$, and a rare risk during winter $(0.66 \%)$.

The above could result from the assumption made on MRT for computing UTCI and the allocated weights used for estimating RiskT. The classification made with the RiskT criterion was used, given the significant effect that direct solar radiation falling on a person has on heat exchange and thermal perception [33]. 


\subsection{Unhealthy Polluted Air Recurrence}

Following Section 2, pollutant concentration was screened for every available dataset, and the $A Q I$ was computed accordingly. Information on the air concentration behavior, during 2019, of $\mathrm{O}_{3}, \mathrm{NH}_{3}, P M_{2.5}$, and $P M_{10}$ is reported on Figure 4.

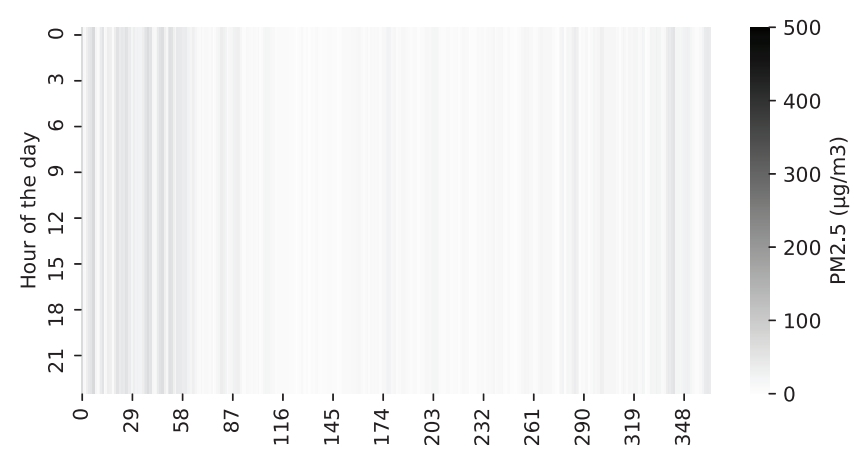

(a)

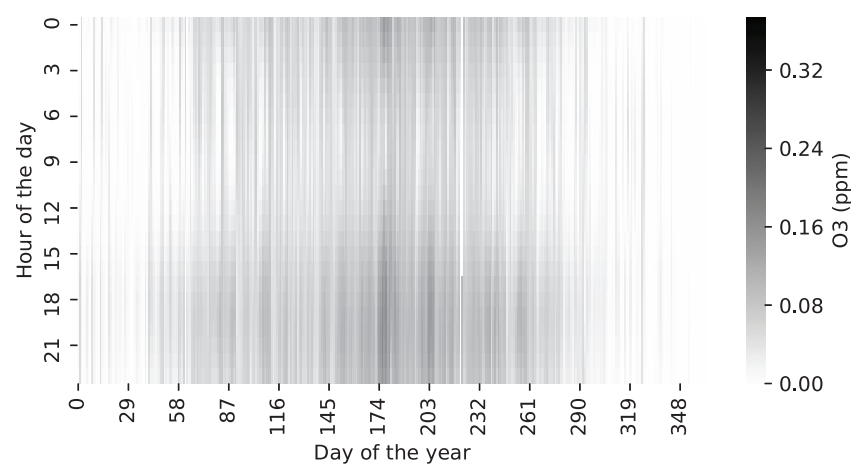

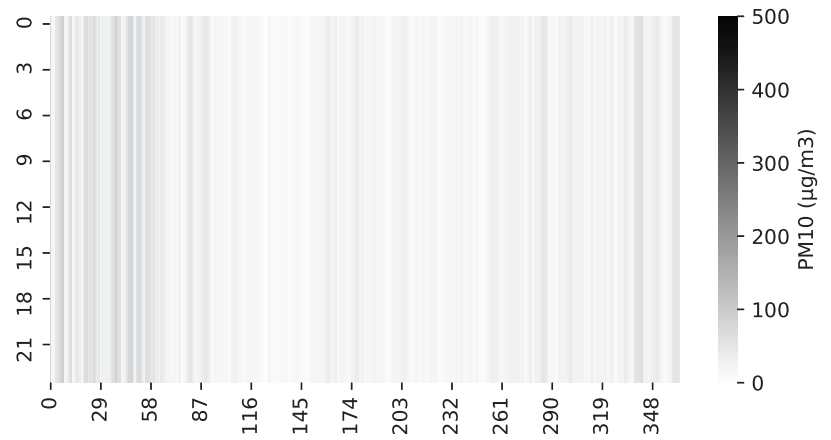

(b)

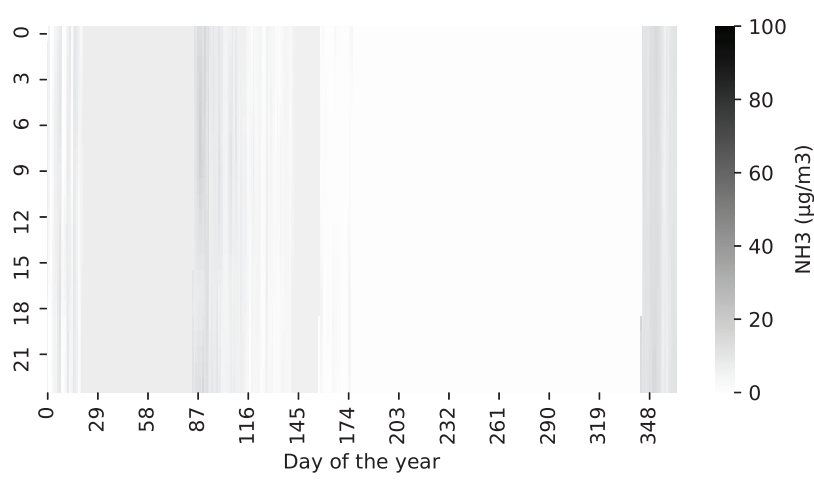

(d)

Figure 4. Degree of air pollution concentration in the $A Q I$, based only on the 2019 values from Milano v. Juvara for (a) $\mathrm{PM}_{2.5}$, (b) $\mathrm{PM}_{10}$, (c) $\mathrm{O}_{3}$, and (d) $\mathrm{NH}_{3}$.

These pollutants' concentrations are reported in way that they display as well the gravity of their accumulation, by setting the gradient ranges from zero to the maximum value that would fall under the greatest hazardous category of $A Q I$ classification. An exception was made for $\mathrm{NH}_{3}$ as the reported values are considerably lower, and the maximum value for display was set to be the limit value before generating a risk to sensitive groups.

From these, it is possible to see how $P M_{10}$ and $O_{3}$ are those representing a greater risk to the citizens' health in the area. In particular, they are at greater risk of $\mathrm{O}_{3}$ accumulation during the afternoons and early mornings by the middle of the year (i.e., summer season).

Looking instead to the complete $A Q I$ analysis, there is a large hour ratio of low air quality during winter time classified as risky $(23.76 \%)$, comparable to the one reported for summer and mid-season (26.3\%); even the yearly risk/total hours (23.03\%); see Table 4 . Thus, the risk frequency can be assumed to be rather similar throughout the seasons. Anyway, Figure 5 clearly shows how the intensity, or gravity, of this air pollution SLODs risk measured with the $A Q I$ is greater during the summer season. 


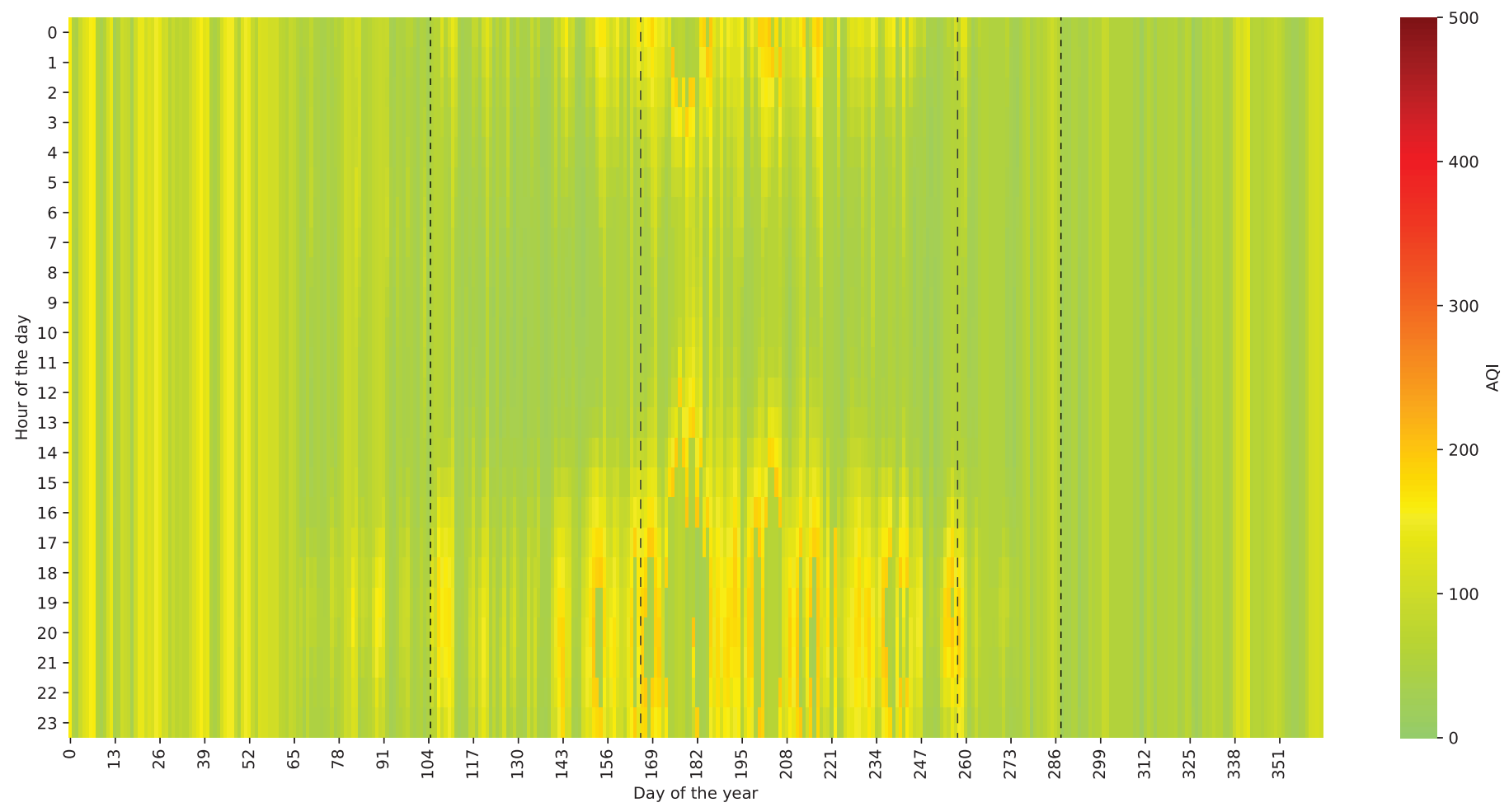

Figure 5. Final degree of air pollution risk in the $A Q I$ based on 2019's values from Milano v. Juvara.

Table 4. Summary results of the allocated air pollution distress, when using $A Q I>100$ as the criterion, differentiated by seasons.

\begin{tabular}{cccc}
\hline & & AQI \\
\hline Season & \# of Hours & Hours at risk & Ratio \\
\hline Whole year & 8760 & 2193 & $25.03 \%$ \\
Summer and mid & 4392 & 1155 & $26.30 \%$ \\
Summer & 2208 & 808 & $18.50 \%$ \\
Mid & 2184 & 347 & $7.90 \%$ \\
Winter & 4368 & 1038 & $23.76 \%$ \\
\hline
\end{tabular}

\subsection{Boosted Health Risk from the Multiple Hazards Effect}

Both SLODs' risks are present and of considerable severity for sensitive groups during summer. However, to clearly state how frequent the potential danger for these demographic groups is, a superimposition assessment was applied as described in Section 2.3 and displayed in Figure 6. 


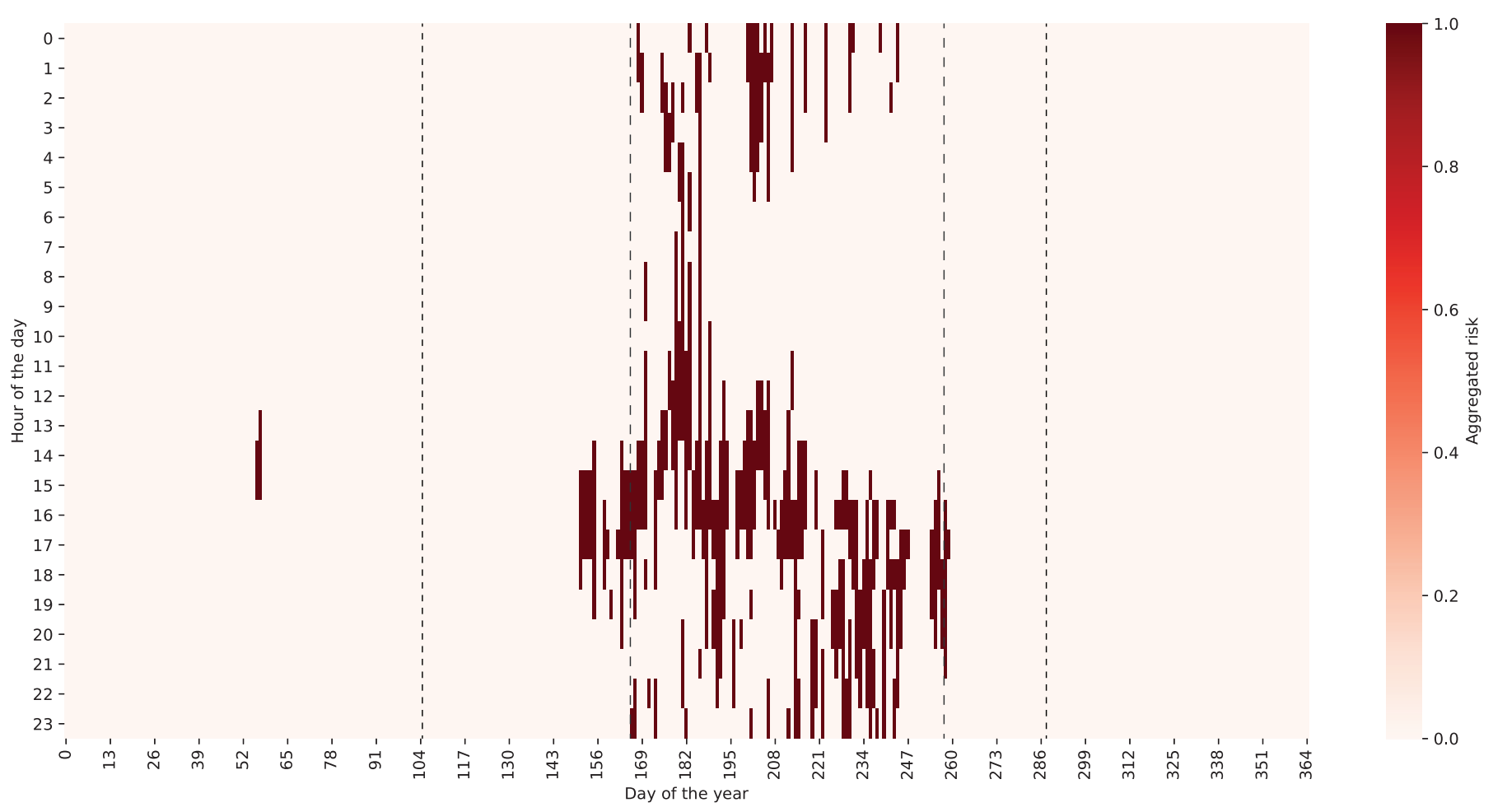

Figure 6. Conjoint risk frequency distribution on a yearly basis for 2019's data extracted from weather and air quality station Milano v. Juvara.

Figure 6 clearly shows how their confluence frequency is concentrated during the summer season ( $9.96 \%$ hour ratio), although some rare conditions were encountered during winter (i.e., last week of February, around DOY $\approx 58$ ), in which there was a severe RiskT $(>0.5)$ and $A Q I(>100)$ representing only $0.11 \%$ of the hours of said period. The frequency by seasons has been compared and condensed in Table 5 .

In addition, one can note that the hazard risk confluence is concentrated in the early mornings and the afternoons.

Table 5. Summary results of the allocated multi-hazard risk, when using $A Q I>100$ as the criterion, differentiated by seasons.

\begin{tabular}{cccc}
\hline & & \multicolumn{2}{c}{ RiskT and AQI } \\
Season & \# of Hours & Hours at Risk & Ratio \\
\hline Whole year & 8760 & 485 & $5.54 \%$ \\
Summer and mid & 4392 & 480 & $10.93 \%$ \\
summer & 2208 & 435 & $9.96 \%$ \\
Mid & 2184 & 45 & $1.02 \%$ \\
Winter & 4368 & 5 & $0.11 \%$ \\
\hline
\end{tabular}

\section{Discussion}

\subsection{Validity of the Preliminary Assessment}

A direct comparison was done between the values obtained for RiskT and UTCI condensed in Table 3, to understand how different the collected samples of the proposed risk criteria and the established, but simplified UTCI were.

UTCI presented a higher risk frequency overall with an absolute algorithmic difference of $0.22 \%$ when comparing yearly data, $1.09 \%$ during summer and mid-season, or $2.48 \%$ during summer. Yet, RiskT presented an absolute $1.37 \%$ more hours of potential thermal stress risk during mid-seasons and $0.66 \%$ during winter when compared to UTCI. 
The absolute algorithmic difference between risk and no risk hours ranged between 19 and $108 \mathrm{~h}$, being least for the 8760 yearly period (i.e., 19) and highest for the $2208 \mathrm{~h}$ in summer. This was considered non-negligible; thus, the classification accuracy was computed, assuming as true values those computed for UTCI, using Equation (2), as 91.56\%; from: 360 False Positives (FPs), 379 False Negatives (FNs), 964 True Positives (TPs), and 7057 True Negatives (TNs).

These results were expected as the assumption of $M R T \approx t_{d b-a i r}$ did not truly express the condition of a person outdoors, and RiskT was configured in a way in which it gave a large significance to the presence of intense $I_{\text {tot }}$ (i.e., $I_{\text {weight }}=0.3$ ). However, with an accuracy over $90 \%$ on a large sample (>8000 measurements), it could be assumed that the approach is feasible for preliminary analyses.

\subsection{Considerable Prevailing Pedestrian Risk}

Certainly, during the summer period in Milan (approximately 18-29\% of the season hours), sensitive groups among citizens or visitors in the areas adjacent to the weather and air quality station Milano v. Juvara were subjected to critical hazards (see Table 2). In addition, in this same period, people outdoors were vulnerable to the conjunct effects of SLODs risk hazards (increasing temperatures and air pollution) for a considerable amount of hours $(9.96 \%)$.

On the other hand, multi-hazard risk arousal during the winter period was unlikely. The seeming outliers were further studied by filtering all collected data; thus, this hazard risk reported for winter resulted from high $I_{t o t}\left(>300 \mathrm{~W} / \mathrm{m}^{2}\right)$, dry air $R H(<30 \%)$, low wind speed $\left(<2 \mathrm{~m} / \mathrm{s}^{2}\right)$, and a high concentration of particulate matter $\left(P M_{2.5}>40.5 \mu \mathrm{g} / \mathrm{m}^{3}\right)$. Although, in these hours, high $t_{d b-a i r}$ were not reported (maximum values were registered around $22.3^{\circ} \mathrm{C}$ ), this does not exclude the possibility of significant thermal stress given the exposure to such solar irradiation $[30,33,34]$.

In addition, winter shall not be assumed as a low risk season as air pollution hazard was present during $23.76 \%$ of the winter time (see Table 4). Figures 5 and $4 \mathrm{a}$ show how most of the hazardous $A Q I$ was correlated to the particulate matter (i.e., $P M_{2.5}$ and $\left.P M_{10}\right)$ concentration trend; given that these values are normally reported as the daily average, larger concentrations could have been experienced by pedestrians in the station's surroundings.

In brief, pedestrians within the built environment close to Milano v. Juvara were subjected to either one of the SLODs hazards for $3032 \mathrm{~h}$ during 2019 (34.61\% of the time) and contemporaneously $485 \mathrm{~h}$ only (5.54\% of the time). However, this gives only an overview of the risk; thus, a frequency profile was drawn to better understand the occurrence trend of these hazards on a daily basis.

Figure 7 displays the frequency density distribution of each and the conjunct SLODs hazard during the day for that location during 2019, allowing identifying the peak moments of the day in which pedestrians were more prone to health deterioration. It is worth noting how the peaks for increasing temperatures and air pollution have a similar growing trend, but a distinct dissipation behavior; this could be attributed to the low capacity of the zone to deposit, absorb, dilute, or dissipate air pollutants; or simply, a pollution concentration increase due to higher pollutant source loads during these time-frames related to anthropogenic activities. 


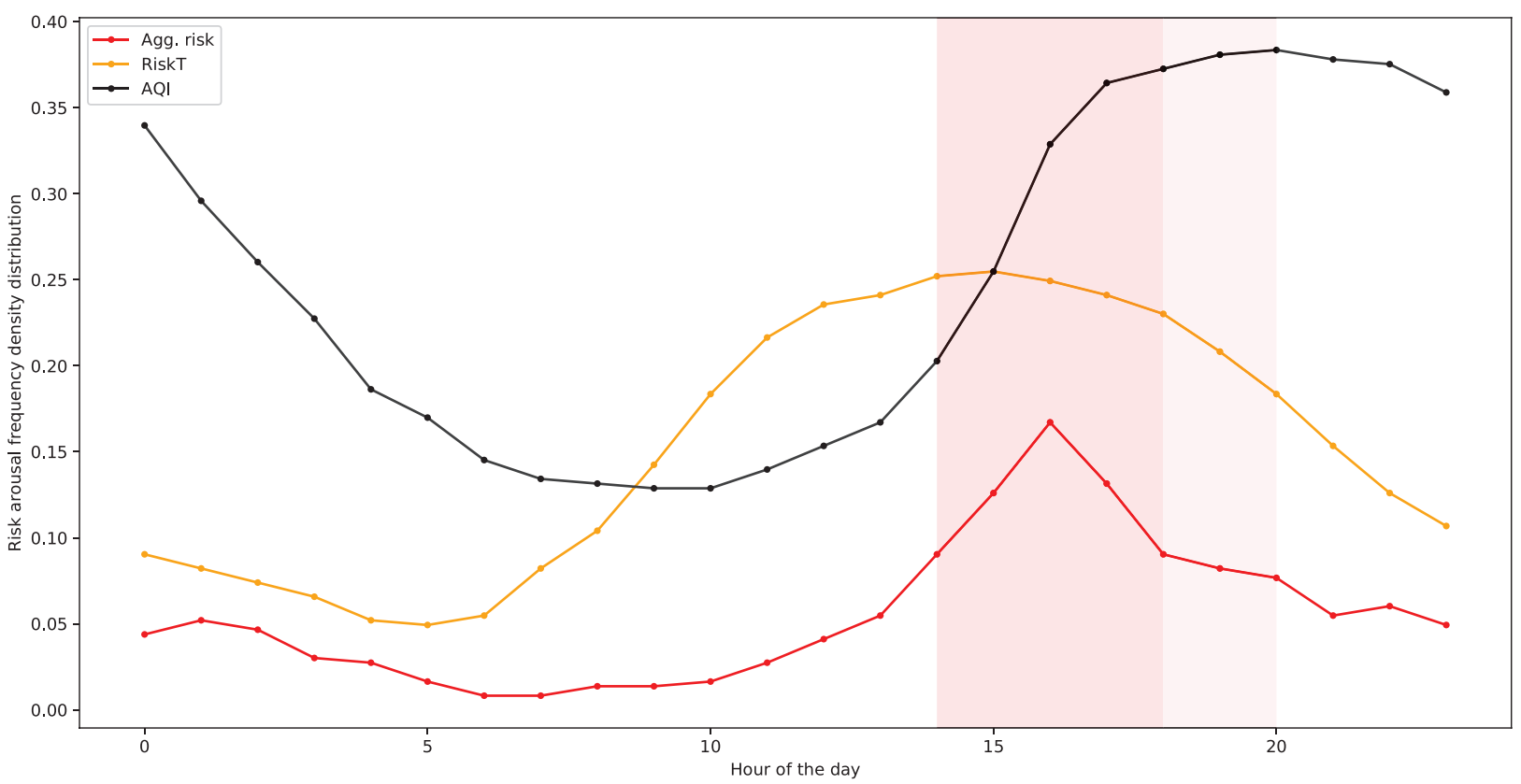

Figure 7. Conjoint risk (Agg. risk) daily profile of the hourly frequency distribution on a yearly basis for 2019's data extracted from Milano v. Juvara.

The constructed profile also allowed identifying the great risk that a person can be exposed during the night-time. People outdoors would be frequently subjected to poor air quality and likewise for those indoors who rely on night cooling or natural ventilation.

Instead, when coupled, the profile shows that pedestrians were most vulnerable at 16:00 (maximum frequency distribution value). Moreover, the most unhealthy period can be established during 14:00 and 18:00, having more than $9 \%$ of those specific $i$-th hours classified as a conjunct hazard moment; and the second most hazardous time-frame was found between 18:00 and 20:00 with a $\approx 8 \%$ ratio.

\subsection{Limitations and Further Work}

The $91.56 \%$ classification accuracy of the proposed criterion is not yet fully satisfactory, and adopting a simplified UTCI result as the true values is only applicable under a few surrounding outdoor conditions within the built environment. The accuracy could be improved by further calibrating the weighting factors used by performing in situ measurements and adjusting MRT for computing UTCI accordingly. These tests and data elaboration will reduce the number of both $F P$ and $F N$, thus increasing the accuracy.

In addition, a normed value could allow capturing and communicating more information on the intensity of the thermal stress and air pollution hazard; as well as providing a rather continuous function, instead of such a discrete trend when applying Booleans.

Further work is planned to include also the physiological characteristics of sensitive groups to further understand the thermal stress variability among those sensitive groups at risk. Furthermore, gathering larger yearly databases and handling time-series missing data would allow making more reliable assumptions and conclusions from the results.

In addition, generating hazard risk frequency daily profiles from environmental data eases future work on the combination of other risk-related analysis, which have a narrower arousal temporal scale (e.g., earthquakes, terrorism attacks), for the superimposing of multiple risk assessment.

\section{Conclusions}

People frequenting dense built environments are susceptible to SLODs, and some of these could arise simultaneously; in particular, people are prone to increasing temperatures 
and air pollution. Coupling their analysis to an integrated approach is limited by the data accessibility, applicability, quality, and granularity. This work proposes a framework that enables and facilitates performing, for a specific site (i.e., Milano v. Juvara's surroundings, Milan, Italy), an outdoor meso-scale multi-hazard-based risk analysis; with which it is possible to obtain a narrower time-frame in which these two events could have affected citizens' health the most.

A weighted fuzzy logic analysis permitted superimposing climatic and air quality distress on an hourly basis, allocated using set healthy and comfortable ranges. Then, it is possible to delineate an average daily multi-hazard arousal profile that can be later used as the input in other risk-related assessments.

Specifically, for the selected case study, findings show that sensitive groups were frequently and greatly at risk during 2019; in fact:

- Summer was found to be the most stressful period for both increasing temperatures and air pollution using a simplified thermal-related index (i.e., RiskT) and the $A Q I$ as separate criteria and/or combined criteria.

- Winter prevalently had low air quality; along with late afternoon and early morning hours on a daily average.

- Thermal stress was reported more frequently instead during midday and afternoon hours.

- During the day, the conjoint effect of climatic and air quality distress was found to be more recurrent between 14:00 and 18:00, with a slight decay during 18:00 and 20:00 (as highlighted in Figure 7).

Author Contributions: Conceptualization, J.D.B.C., N.M., G.S., T.P., E.Q., and F.R.; methodology, J.D.B.C., N.M., and G.S.; validation, J.D.B.C., G.S., and E.Q.; formal analysis, J.D.B.C., N.M., and F.R.; investigation, J.D.B.C. and N.M.; resources, G.S.; data curation, J.D.B.C.; writing, original draft preparation, J.D.B.C.; writing, review and editing, J.D.B.C., N.M., G.S., and E.Q.; visualization, J.D.B.C. and N.M.; supervision, G.S. and E.Q.; project administration, G.S. and E.Q.; funding acquisition, G.S., E.Q., and T.P. All authors read and agreed to the published version of the manuscript.

Funding: This research was funded by MIUR (the Italian Ministry of Education, University and Research) under the project BE S2ECURe - (make) Built Environment Safer in Slow and Emergency Conditions through behavioral assessed/designed Resilient solutions, Grant Number 2017LR75XK.

Institutional Review Board Statement: Not applicable.

Informed Consent Statement: Not applicable.

Data Availability Statement: Publicly available datasets were analyzed in this study. This data can be found here: https://www.arpalombardia.it/Pages/Temi-Ambientali.aspx.

Conflicts of Interest: The authors declare no conflict of interest.

\section{References}

1. United Nations, Department of Economic and Social Affairs, Population Division. World Urbanization Prospects: The 2018 Revision; Technical report; United Nations: New York, NY, USA, 2019.

2. World Health Organization. Quantitative Risk Assessment of the Effects of Climate Change on Selected Causes of Death, 2030s and 2050s; WHO Press: Geneva, Switzerland, 2014.

3. World Health Organization. Ambient Air Pollution: A Global Assessment of Exposure and Burden of Disease; World Health Organization: Geneva, Switzerland, 2016; p. 121.

4. United Nations. Transforming Our World: the 2030 Agenda for Sustainable Development; United Nations: New York, NY, USA, 2015.

5. Lee, J.Y.; Kim, H. Projection of future temperature-related mortality due to climate and demographic changes. Environ. Int. 2016, 94, 489-494. [CrossRef] [PubMed]

6. Jackson, J.E.; Yost, M.G.; Karr, C.; Fitzpatrick, C.; Lamb, B.K.; Chung, S.H.; Chen, J.; Avise, J.; Rosenblatt, R.A.; Fenske, R.A. Public health impacts of climate change in Washington State: Projected mortality risks due to heat events and air pollution. Clim. Chang. 2010, 102, 159-186. [CrossRef]

7. UNFCCC. Slow Onset Events; Technical report; United Nations: New York, NY, USA, 2012. 
8. U.S. Environmental Protection Agency. Urban heat island basics. In Reducing Urban Heat Islands: Compendium of Strategies I Heat Island Effect I US EPA; U.S. Environmental Protection Agency: Washington, DC, USA, 2008.

9. Rosenzweig, C.; Solecki, W.D.; Romero-Lankao, P.; Mehrotra, S.; Dhakal, S.; Ibrahim, S.A. Climate Change and Cities: Second Assessment Report of the Urban Climate Change Research Network; Cambridge University Press: Cambridge, UK, 2018.

10. Niemenmaa, V.; Happach, B.; Kubat, J.; Otto, J.; Pirelli, L.; Simeonova, R.; Zalega, A.; Wisniewska-Danek, K.; Radecka-Moroz, K.; Wojciechowski, J.; et al. Air pollution: Our Health Still Insufficiently Protected; Technical report; ECA: Luxembourg, 2018. [CrossRef]

11. Colaninno, N.; Morello, E. Modelling the impact of green solutions upon the urban heat island phenomenon by means of satellite data. J. Physics: Conf. Ser. 2019, 1343, 012010. [CrossRef]

12. Fuladlu, K.; Riza, M.; Illkan, M. The Effect of Rapid Urbanization on the Physical Modification of Urban Area. In Proceedings of the International Conference on Architecture and Built Environment with AWARDs, Venice, Italy, 22-24 May 2018; pp. 1-9.

13. Paolini, R.; Mainini, A.G.; Poli, T.; Vercesi, L. Assessment of thermal stress in a street canyon in pedestrian area with or without canopy shading. Energy Procedia 2014, 48, 1570-1575. [CrossRef]

14. Jamei, E.; Rajagopalan, P.; Seyedmahmoudian, M.; Jamei, Y. Review on the impact of urban geometry and pedestrian level greening on outdoor thermal comfort. Renew. Sustain. Energy Rev. 2016, 54, 1002-1017. [CrossRef]

15. Stewart, I.D.; Oke, T.R. Local climate zones for urban temperature studies. Bull. Am. Meteorol. Soc. 2012, 93, 1879-1900. [CrossRef]

16. Udristioiu, M.T.; Velea, L.; Bojariu, R.; Sararu, S.C. Assessment of urban heat Island for Craiova from satellite-based LST. In AIP Conference Proceedings; AIP Publishing LLC: Melville, NY, USA, 2017; Volume 1916, p. 040004.

17. Sassi, M.Z.; Fourrié, N.; Guidard, V.; Birman, C. Use of Infrared Satellite Observations for the Surface Temperature Retrieval over Land in a NWP Context. Remote. Sens. 2019, 11, 2371. [CrossRef]

18. Khamchiangta, D.; Dhakal, S. Time series analysis of land use and land cover changes related to urban heat island intensity: Case of Bangkok Metropolitan Area in Thailand. J. Urban Manag. 2020, 9, 383-395. [CrossRef]

19. Ketterer, C.; Matzarakis, A. Mapping the Physiologically Equivalent Temperature in urban areas using artificial neural network. Landsc. Urban Plan. 2016, 150, 1-9. [CrossRef]

20. Sharifi, E.; Lehmann, S. Correlation analysis of surface temperature of rooftops, streetscapes and urban heat island effect: Case study of central Sydney. J. Urban Environ. Eng. 2015, 9, 3-11. [CrossRef]

21. Vienneau, D.; De Hoogh, K.; Briggs, D. A GIS-based method for modelling air pollution exposures across Europe. Sci. Total. Environ. 2009, 408, 255-266. [CrossRef] [PubMed]

22. Mackey, C.; Galanos, T.; Norford, L.; Roudsari, M.S.; Bhd, N.S. Wind, Sun, Surface Temperature, and Heat Island: Critical Variables for High-Resolution Outdoor Thermal Comfort Payette Architects, United States of America Massachusetts Institute of Technology, United States of America University of Pennsylvania. In Proceedings of the 15th IBPSA Conference, San Francisco, CA, USA, 7-9 August 2017; pp. 985-993.

23. Salmond, J.A.; Williams, D.E.; Laing, G.; Kingham, S.; Dirks, K.; Longley, I.; Henshaw, G.S. The influence of vegetation on the horizontal and vertical distribution of pollutants in a street canyon. Sci. Total. Environ. 2013, 443, 287-298. [CrossRef] [PubMed]

24. ARPA Lombardia. Dati e Indicatori, ARPA Lombardia: Rosellini, Milano, Italy. Available online: https://www.arpalombardia.it (accessed on 25 March 2020 ).

25. Salvalai, G.; Enrico, Q.; Blanco Cadena, J.D. Built environment and human behavior boosting Slow-onset disaster risk. In Heritage 2020; Green Lines Institute for Sustainable Development: Coimbra, Portugal, 2020; pp. 199-209.

26. ISTAT. Statistiche Istat, ISTAT: Rome, Italy. Available online: http:/ / dati.istat.it/ (accessed on 16 January 2020 ).

27. (EEA), Observed Annual Mean Temperature Change from 1960 to 2019 and Projected 21st Century Change Under Different Emissions Scenarios in Europe. Available online: https://www.eea.europa.eu/data-and-maps/figures/trends-in-annualtemperature-across-1 (accessed on 31 March 2020).

28. European Environment Agency. Air Quality in Europe-2019 Report. EEA Report No 10/2019; Technical report; European Environment Agency: Copenhagen, Denmark, 2019. [CrossRef]

29. Bröde, P.; Fiala, D.; Blazejczyk, K.; Epstein, Y.; Holmér, I.; Jendritzky, G.; Kampmann, B.; Richards, M.; Rintamäki, H.; Shitzer, A.; et al. Calculating UTCI equivalent temperature. In Environmental Ergonomics XIII; University of Wollongong: Wollongong, Australia, 2009; pp. 49-53.

30. ANSI/ASHRAE. ANSI/ASHRAE Standard 55-2017 : Thermal Environmental Conditions for Human Occupancy; ASHRAE Inc.: Atlanta, GA, USA, 2017.

31. U.S. Environmental Protection Agency. Guidelines for the Reporting of Daily Air Quality—The Air Quality Index (AQI); Technical report; EPA: Washington, DC, USA, 2006.

32. Comune di Milano. Portale Open Data /Comune di Milano, Comune di Milano: Milano Italia. Available online: http: / / dati.comune.milano.it/ (accessed on 16 January 2020).

33. Zani, A.; Mainini, A.G.; Blanco Cadena, J.D.; Schiavon, S.; Arens, E. A New Modeling Approach for the Assessment of the Effect of Solar Radiation on Indoor Thermal Comfort. In Procceeding of the Building Performance Analysis Conference and SimBuild, Chicago, IL, USA, 26-28 September 2018.

34. Arens, E.; Hoyt, T.; Zhou, X.; Huang, L.; Zhang, H.; Schiavon, S. Modeling the comfort effects of short-wave solar radiation indoors. Build. Environ. 2015, 88, 3-9. [CrossRef] 